\title{
Estado Do Conhecimento Sobre Ensino Na Contabilidade No Congresso Anpcont 2007-2019
}

\author{
Marcos Laffin $^{1 *}$, Nathália Helena Fernandes Laffin ${ }^{2}$, Jhonatan Hoff ${ }^{3}$ \\ ${ }^{I}$ Doutor - UFSC Universidade Federal de Santa Catarina Programa de Pós-Graduação em Contabilidade \\ ${ }^{2}$ Doutora - USP Faculdade Borges de Mendonça \\ ${ }^{3}$ Mestre - UFSC Universidade Federal de Santa Catarina Programa de Pós-Graduação em Contabilidade \\ *Corresponding Author: Marcos Laffin, Doutor - UFSC Universidade Federal de Santa Catarina \\ Programa de Pós-Graduação em Contabilidade
}

\begin{abstract}
Este artigo ao corroborar com a importância da realização das catorze (14)edições do Congresso ANPCONT, aborda o tema "ensino" a partir dos trabalhos apresentados nesse evento e discutidos na área temática de Educação e Pesquisa em Contabilidade. O objetivo da pesquisa foi identificar qual é a concepção de ensino que fundamenta os trabalhos apresentados nas edições do ANPCONT no período de 2007 a 2019 na área temática de "Educação e Pesquisa em Contabilidade”.Quanto ao objetivo é um estudo exploratório e os procedimentos expõem a base bibliográfica com abordagem qualitativa pela análise de conteúdo. Do estudo realizado, concluiu-se que a maioria dos trabalhos analisados não segue um ideário pedagógico definido. Identificaram-se diversas tendências dentro de um mesmo referencial, as quais geralmente se baseiam em autores da própria área contábil, sem fundamentos da epistemologia educacional, referindo-se ao ensino numa visão pragmática que encontra ressonância na racionalidade técnica, em uma concepção voltada ao desenvolvimento de habilidades e competências para suprir as necessidades do mercado de trabalho. Ainda que existam trabalhos que apresentem uma referência divergente do atual modeloda educação contábil, estes se apoiam em argumentos que remetem o ensino a um processo mecânico com a finalidade de suprir as demandas do capital.
\end{abstract}

Key Words: Contabilidade. Ensino. Ensino-aprendizagem.

\section{INTRODUÇÃO}

A Associação Nacional dos Programas de Pós-Graduação em Ciências Contábeis - ANPCONT foi instituída formalmente em 30 de janeiro de 2006, decorrente de discussõesiniciadas num grupo de coordenadores de programas de pós-graduação stricto sensu. Oprincípio das discussões ocorreu no ano de 2005 com a percepçãoda necessidade de estruturar uma entidade acadêmica representativa dos objetivos e das finalidades dos programas de pós-graduaçãostricto sensu em Contabilidade no Brasil.

O primeiro Congresso ANPCONT ocorreu em junho de 2007 na cidade de Gramado no Rio Grande do Sul e, desde então,mantém a regularidade anual de evento específico da área de Ciências Contábeis, com a particularidade de discussões temáticas relevantes ao desenvolvimento a respeito doconhecimento contábil.

Diferentes estratégias na organização das edições do congresso são definidas e utilizadas com o delineamento de"Tema Central”. Assim, realizam-seseções temáticas, interativas, palestras, Workshops, painéis e mostra de iniciação científica, as quaisvêm sendo aprimoradas e se constituemnum espaço de discussão de questões inerentes à prática profissional com sólida interseção no campo acadêmico.

As edições do congresso têm sido organizadas pelas seguintes áreas de concentração: Auditoria e Tributos (AT); Contabilidade Financeira e Finanças (CFF); Contabilidade e Setor Público (CSP); Controladoria e Contabilidade Gerencial (CCG); Educação e Pesquisa em Contabilidade (EPC); Tópicos Especiais em Contabilidade (TEC); Consórcio Doutoral e Mestral (CDM); Artigos Tecnológicos (AT) e; Iniciação Científica (IC).

No ano de 2020,foi realizada a XIV Edição do Congresso ANPCONT. Excepcionalmente em função da pandemia mundial, COVID-19, por orientação dos órgãos de saúde e segurança o evento 
foirealizado na modalidade virtual. Denota-se nessa temporalidade a importância do Congresso pela qualificação das discussões, pelas conquistas e avanços da área, bem como demarcando a assertiva do grupo de proponentes que, de forma desafiadora, particularizam e ampliam as oportunidades teóricopráticas do conhecimento contábil no âmbito das Ciências Sociais Aplicadas.

Com a finalidade de evidenciar uma das contribuições temáticas nas 14 edições da ANPCONT, este artigo aborda o tema "ensino" a partir de uma pesquisa dos trabalhos apresentados na área de concentração "Educação e Pesquisa em Contabilidade". Nesse contexto, a questão que norteou a pesquisa foi quais são as concepções de ensino que emergem dos trabalhos apresentados nas edições da ANPCONT no período de 2007 a 2019? O objetivo consiste em identificar qual é a concepção de ensino que fundamenta os trabalhos apresentados nas edições do ANPCONT no período de 2007 a 2019 na área temática de "Educação e Pesquisa em Contabilidade".

Destaca-se a relevância desse estudo,ao mesmo tempo que expressaa importância das finalidades de constituição da ANPCONT, a qual apresenta, entre osobjetivos, o de congregar e atuar na área da educação contábilcom a interação dos programas de Mestrado e Doutorado em Ciências Contábeis no Brasil. Dessa forma,representa os interesses e os propósitos da pesquisa e do ensino em colaborar no desenvolvimento de parcerias interinstitucionais para o desenvolvimento do conhecimento contábil, caracteriza-se também por inventariar a produção acerca do tema "ensino" apresentados e discutidos nas edições de 2007 a 2019 da ANPCONT, destacando-se como tema basilar dos objetivos dos programas stricto sensu em ciências Contábeis.Assim, esta pesquisa sobre o "ensino" conjuga, tantos os objetivos constitutivos da ANPCONT, quanto dos programas de pós-graduação stricto sensu em Ciências Contábeis, evidenciando um inventário/levantamento das concepções sobre o tema e ascontribuições para a área.

\section{ABORDAGENS E CONCEPÇÕES SOBRE ENSINO}

"Quem ensina aprende ao ensinar e quem aprende ensina ao aprender" (Freire, 1997, p. 25).

A tese de Freire remete a uma reflexão permanente acerca do exercício intencional da docência, particularmente, a respeito da atividade de ensino como ponto de partida do trabalho do professor. Esta tese produz desdobramentos, os quais se vinculam ao seu princípio: o ensino não ocorre sem a aprendizagem, de forma que este é um processo inseparável, pois esses elementos estão intimamente relacionados e mantêm uma interdependência para que ocorram. Sendo processo relacional, requer atividades diferenciadas na sua realização.

A ênfase na discussão a seguir é sobre o ensino, o qual compreende as atividades desempenhadaspelo professor e que se relacionam com as que os estudantes realizam para a aprendizagem. Evidenciando,dessa forma, que aquilo que o professor faz na prática de ensino se relaciona com o que os estudantes intentampara asaprendizagens.

No campo educacional, são muitas as formulações conceituais acerca do conceito de ensino, decorrentes das diferentes matrizes epistemológicas e, portanto, sobre o modo de compreensão e de realização.

Para Libâneo, o ensino "corresponde às ações, aos meios e às condições para a realização da instrução, ou seja, o ensino é composto pela instrução”. (2004, p.23). O ensino é, portanto, uma ação intencional, ação de alguém que ensina, o qual denominamos de professor, para um sujeito, o qual designamos como estudante, que busca um conhecimento na forma de aprender, e nestas ações envolve o objeto da ação que denominamos de conteúdos. Esta ação que se faz por sujeitos, meios e condições denominamos de processo ensino-aprendizagem.

O ensino também pode ser compreendido como processo de "instruir alguém a respeito daquilo que não sabe ou sabe inadequadamente”. (NERICI, 2015, p.100).

A partir de tais premissas conceituais, é possível entender o ensino como um processo que requer o domínio de algo (conhecimento), por parte de alguém (professor), elaborado num determinado tempo (perspectiva histórica), em que instruirá alguém (estudante) sobre algo que ainda não sabe ou sabe inadequadamente (temporalidade dos saberes). A partir dessa premissa, é possível alargar a sua compreensão como a que considera que o sujeito aprendente é aquele que já possui algum saber, com experiências prévias sobre determinados assuntos e pelo processo de ensino poderá ampliar esse saber e compreendê-lo em maior profundidade e comoutras perspectivas. 
Pérez Gómez (1998), ao discutir as diferentes perspectivas do ensino apresenta enfoques do desenvolvimento do conceito de ensinar e as implicações desse fazer. Ao referenciar o ensino como tradicional dimensiona os conhecimentos disciplinares e escolares como transmissão, práticas essas as quais convertem o conhecimento em memorização e não para a compreensão dos significados.

Também o ensino como treinamento de habilidades, desde as mais simples até as mais complexas geralmente passam por práticas dissociadas de conteúdo e significados socioculturais o que permite elevar um processo de desmotivação para as aprendizagens.

No enfoque do ensino como desenvolvimento natural se processa um caráter idealista de individualidade. Contudo o desenvolvimento humano é um processo complexo que envolve cultura e interações sociais motivos pelos quais o ensino escolar não encontra fundamentos para se converter em processos individuais.

Na perspectiva do ensino como produção de mudanças conceituais o estudante assume a centralidade do processo pois se concebe que a aprendizagem ocorre quando o estudante consegue mobilizar seus esquemas de conhecimentos com o confronto de suas condições de vida cotidiana.

Assim, a perspectiva conceitual, que é factível a toda formulação intencional do processo de ensinar, deve considerar que ensinar é possuir o domínio do conhecimento a ser transmitido/construído para alguém que deseja melhor compreendê-lo. Conforme assinalado anteriormente, a concepção sobre o ato de ensinar envolve outros valores e concepções pelas quais ele se expressa em seus métodos de realização. Dessa forma, com intenção de marcar nossa concepção progressista sobre o ensino, inferese que o termo "transmitir conhecimento" assume neste texto, oentendimento histórico da ocorrência do conhecimento como objeto de ensino para que na sequência pedagógica possa ser confrontado e questionado em diferentes perspectivas teórico-metodológicas. Ensinar assume a concepção de construção na relação entre sujeitos, objetos de conhecimentos e compreensão da prática educativa no mundo sociocultural contextualizado.

Nessa visão, o ensino como objeto da educação do ser humano, ao ser compreendido em sua função mediadora entre a condição humana e o contexto social dos sujeitos, requer a intencionalidade dos objetivos. Da mesma forma, o professor como sujeito que ensina e aprende, possui atividades específicas, haja vista que deve organizar otrabalho de ensinar de forma intencional, evidenciando as concepções de mundo, os sujeitos, a sociedade, o conhecimento entre outras categorias pedagógicasas quais implicam o processo ensino-aprendizagem.

Entende-se que pela atividade de ensino

o trabalho educativo é o ato de produzir, direta e intencionalmente, em cada indivíduo singular, a humanidade que é produzida histórica e coletivamente pelo conjunto dos homens. Assim, o objeto da educação diz respeito, de um lado, à identificação dos elementos culturais que precisam ser assimilados pelos indivíduos da espécie humana para que eles se tornem humanos e, de outro lado e concomitantemente, à descoberta das formas mais adequadas para atingir esse objetivo (SAVIANI, 1997, p. 17).

Ensinar na perspectiva intencional requer planejar de forma contextualizada o processo de trabalho do professor e,nessa atividade,as concepções sobre o próprio ensino podem ser apreendidas pelo planejamento, pelo conteúdo, pela prática pedagógica, pelo conjunto de ações que norteiam a concepção de trabalho em educação, dos objetos e sujeitos relacionais, das históricas e contextuais concepções de mundo.

\subsection{Abordagens sobre o ensino}

Ao compreender o processo ensino-aprendizagem como atividade complexa que se desenvolve mediante diferentes concepções, depreende-se que o conhecimento acerca das diferentes abordagens do processo, "bem como, a análise crítica e reflexiva dessas, representa um elemento essencial na sistematização e organização de uma concepção ampliada do conhecimento contábil e sua aplicabilidade" (LAFFIN, 2005, p. 24).

Parte-se do pressuposto de que o processo ensino e aprendizagem pode ser compreendido por diversas formas. Mizukami (1986) apresenta diferentes abordagens sobre o ensino que permitem interpretar criticamente os elementos e concepções que permeiam o fenômeno educativo. Trata-se de distintas formas que buscam uma aproximação do processoensino-aprendizagem, baseadas em mediações 
historicamente possíveis e que comportam, em pelo menos alguns dos aspectos, questões intrínsecas ao fenômeno educacional e, portando, merecem ser analisadas de forma crítica (MIZUKAMI, 1986,pp.1-6).

Ressaltamos a necessária explicação no uso das categorias organizados por Mizukami (1986),que se justificam neste trabalho, em função do critério de unicidade para a coesão de análise ao termo "ensino" identificados nos artigos. A classificação dada pela autora às diferentes abordagens nos permitem utilizar a mesma terminologia num diálogo de linguagem pedagógica sem a necessidade de estabelecer um dicionário de significados com outros referenciais em função dos objetivos desta pesquisa. Dessa forma, o que se pretendeu foi estabelecer uma matriz de compreensão categorial que permita situar as diferentes abordagens utilizadas pelos respectivos autores dos artigos selecionados nesta pesquisa com a proposta de Mizukami.Igualmente, com razão e importância, se reconhece em diferentes referenciais a existência de bibliografias análogas na categorização das abordagens.

Outra justificativa fundamental para utilizar as categorias organizadas por Mizukami em 1986 é que elas ainda são atuais e refletem muitas práticas escolares na atualidade. Tais categorias dizem respeito a atualidade dessa referência e de estarem em aberto para intervenções pedagógicas no enfrentamento de problemas cotidianos que requerem a articulação entre teoria e prática como produto do trabalho docente. Além de que as abordagens constituem tempos históricos que denotam contribuições da história da educação e que são reconhecidas em muitos contextos como práticas em movimento e em dados contextos como hibridas em sua complementação.

As concepções de ensino categorizadas pela autora são divididas em tradicional, comportamentalista, humanista, cognitivista e sociocultural. A cada uma dessas, a autora apresenta pressupostos sobre a concepção de homem, mundo, sociedade e cultura, conhecimento, educação, escola, ensinoaprendizagem, professor-aluno, metodologia e avaliação. Mizukami (1986) afirma que enquanto algumas abordagens estão ancoradas claramente em um referencial teórico, outras são intuitivas, baseadas na prática ou na repetição de modelos (MIZUKAMI,1986, pp.1-6).

A abordagem tradicional, a qual se assemelha à educação bancária criticada por Freire (1975), parte do pressuposto de que o processo de aprendizagem seja baseado na capacidade de armazenar informações, numa concepção em que o conhecimento humano possui um caráter cumulativo adquirido por meio da transmissão de conhecimentos. O processo ensino-aprendizagem nessa abordagem dá ênfase às situações de sala de aula, em que o professor, detentor do conhecimento, assume o papel central na instrução dos alunos. Esses, por sua vez, assumem um papel passivo no processo ensino-aprendizagem, limitando-se somente a execução de prescrições. Caracterizada pela transmissão de conhecimentos, a abordagem tradicional privilegia a memorização de definições e conceitos enquanto não há a preocupação com formação do pensamento reflexivo, propiciando, assim, a formação de sujeitos com reações rotuladas e automáticas, uma compreensão parcial do seu objeto de formação (MIZUKAMI, 1986, p.7-18).

Enquanto a abordagem tradicional entende o conhecimento como algo cumulativo, a concepção comportamentalista fundamenta-se no entendimento de que o conhecimento é uma nova descoberta para o indivíduo, essa já existente no contexto exterior. Nesta abordagem, o comportamento humano é plausível de mudanças e, portanto, pode ser ajustado. Os seguidores desta linha de pensamento, também conhecida como behaviorista, consideram que o conhecimento é um resultado da experiência. Dessa forma, os principais objetivos do processo ensino-aprendizagem pautam-se no desenvolvimento de habilidades que resultam em competências. Entendendo o ensino como um treinamento que visa aperfeiçoar o comportamento, a abordagem comportamentalista procura transmitir conhecimentos e habilidades básicas, como preceitos éticos e práticas sociais (MIZUKAMI, 1986, pp. 19-36).

$\mathrm{Na}$ abordagem humanista, o ensino assume um significado amplo, em que a ênfase do processo é voltada ao sujeito como principal responsável pela construção do conhecimento, em uma concepção construtiva do processo de vir a ser, no qual o indivíduo é considerado como um projeto permanente e inacabado. A partir dessa visão, o processo de ensino objetiva o desenvolvimento da autoaprendizagem, ou seja, de aprender a aprender. Com isso, o processo de construção do conhecimento ocorre por meio da atribuição de significados das experiências vivenciadas pelo indivíduo. Não obstante, explicita-se o destaque de que as relações interpessoais assumem no processo de ensino e na criação de uma consciência autônoma, com a finalidade de que sejam dadas condições aos alunos para que esses se tornem "pessoas de iniciativa, de responsabilidade, de 
autodeterminação, de discernimento, que soubessem aplicar-se a solução de seus problemas e que tais conhecimentos os capacitassem a se adaptar com flexibilidade as novas situações, a novos problemas"(MIZUKAMI, 1986, pp. 37-58).

$\mathrm{Na}$ abordagem cognitivista, o conhecimento é visto como um processo construtivo interacionista, em que a aprendizagem extrapola a interação do estudante com o meio externo a ele e passa a considerar as emoções e os processos cognitivos na articulação com a construção do conhecimento. Nessa abordagem, consideram-se as formas com as quais os indivíduos interagem com o ambiente e, a partir disso, adquirem novos conhecimentos baseando-se em reestruturações sucessivas, ou seja, todo novo conhecimento é assimilado a uma estrutura já existente, despontando assim, uma reestruturação nosconhecimentos. Considerando questões centrais do indivíduo, como a forma de organização do pensamento e estilos cognitivos, a abordagem cognitivista entende que o desenvolvimento da inteligência deve ser centrado no sujeito (MIZUKAMI, 1986, pp.59-84).

$\mathrm{Na}$ abordagem sociocultural,enfatizam-se os aspectos sócio-político-cultural, em que o indivíduo é entendido como um sujeito inserido em um contexto histórico. Partindo do entendimento de que o homem é o sujeito da própria educação, o processo de ensino deve promover o indivíduo em uma proposição libertadora, superando a relação opressor-oprimido e não simplesmente servindo de instrumento para ajustar o indivíduo à sociedade. A abordagem sociocultural compreende que o conhecimento é construído a partir do ato de reflexão acerca da realidade, fazendo com que o sujeito tome consciência de sua historicidade. Tal processo de conscientização, constituído pelo constante desvelamento da realidade, possui sua essência baseada na dialogicidade em que educador e educando possuem uma relação horizontal, superando o autoritarismo do sistema de educação bancária, fazendo do ensino uma prática transformadora, capaz de oferecer condições para que o aluno questione sua própria realidade e possa intervir como agente de mudança no contexto em que está inserido (MIZUKAMI, 1986, pp. 85-103).

A questão central em discutir tais abordagens reside no fato de que as concepções de ensino adotadas podem resultar em diferentes modelospedagógicos. Denota-se que cada uma das abordagens do ensino é fundamentada em contextos históricos e sociais, procurando explicar a realidade presente. Posto isso, entende-se que tanto o conhecimento contábil, quanto as concepções de ensino precisam descrever uma conjuntura condizente com as problemáticas da realidade que os circunda (LAFFIN, 2005 p.190).Além do mais, torna-se imprescindível contemplar os fundamentos conceituais pertinentes àárea para compreender os conhecimentos produzidos.

\section{Metodologia}

A pesquisa realizada buscou identificar as concepções acercados conceitos de ensino que emergem dos trabalhos apresentados nas edições da ANPCONT no período de 2007 a 2019. Oobjetivo desteartigo é exploratório, e realizado com os recursos da pesquisa bibliográfica, a qual permite aproximar o tema "ensino" a partir dos trabalhos apresentados no ANPCONT. Vale lembrar que se busca uma perspectiva do conceito em suas diferentes acepções quando utilizado em relação ao processo ensino-aprendizagem. Por sua vez, caracteriza-se como bibliográfica pelo fato de os artigos aqui analisados submeterem-se ao evento e, neste,terem sido avaliados por comissão e pares, bem como publicados na página do evento nas respectivas datas do congresso. Com base nisso, ao inventariar os trabalhos apresentados e discutidos foi possível sistematizar a produção acumulada sobre o tema. Foi utilizada a categorização organizada por Mizukami (1986) para depreender o conceito de ensino utilizado nos artigos.

O procedimento para a seleção do tema foiparticularizado, visando àinvestigação na análise nos seguintes passos: inicialmente selecionou-se a categoria de concentração Educação e Pesquisa em Contabilidade nas edições da ANPCONT realizadas no período de 2007 a 2019. Na sequência selecionaram-se os artigos voltados à discussão de questões relativas ao ensino em contabilidade, com base no título, resumo e palavras-chave. Após a seleção dessa etapa,identificaram-se os objetivos do artigo para validar a pertinência do trabalho e do tema e objetivo nas discussões desses.

Nessa etapa,inventariaram-se221 artigos apresentados no Congresso ANPCONT no período de 2007 a 2019 na Categoria Educação e Pesquisa em Contabilidade. Destes, selecionaram-se77 artigos que possuíam o ensino como tema central. Em seguida, leu-se o resumo e identificou-se no corpo do texto a utilização do conceito de ensino como fundamentos para a abordagem do problema discutido no trabalho. Nesse procedimento,do total de artigos apresentados na temática Educação e Pesquisa em 
Contabilidade, analisaram-see foram identificados 49 artigos cujo conteúdo atendia aos objetivos do estudo que foi de identificar as concepções de ensino nos trabalhos do ANPCONT entre 2007 a 2019. A Tabela 1 sintetiza a quantidade de artigos selecionados de acordo com cada critério.

Tabela1. Artigos por critério de seleção

\begin{tabular}{|l|l|}
\hline Artigos apresentados na área temática de Educação e Pesquisa em Contabilidade & 221 \\
\hline Artigos selecionados pelo critério de título e objetivos pedagógicos & 77 \\
\hline Artigos que abordam o conceito de ensino & 49 \\
\hline
\end{tabular}

Fonte: Dados da Pesquisa

Os trabalhos selecionados constam dispostos em ordem cronológica no Anexo 1. Além disso, organizaram-se os 49 artigos que compõe a amostra deste estudo em um quadro com os seguintes itens de identificação: a) autor; b)título do artigo; c) ano do congresso.

Assim, a descrição dos dados e sua análise discursiva inscreveram-se sobre os conteúdos manifestos e conceitos auferidoso que permitiu inventariar o conceito de ensino. Corroborando o assunto, os dados da análise discursiva 'não constituem uma realidade, ' mas 'traduzem uma realidade' quer estejam no campo das ideias ou das teorias e/ou conceitos utilizados(MORAES, 2004, p. 199). Nessa perspectiva, o uso do conceito de ensino, nos textos em análise, emerge de contextos socioculturais particulares, os quais constituem um discurso em movimento com diferentes vieses pedagógicos.

A análise de conteúdo, como importante recurso nas formas de interpretar e compreender o objeto de análise, assume com predominância o aspecto qualitativo e descritivo da informação objeto de pesquisa. Nesse sentido, a expectativa de compreensão recai sobre a forma de pensamento de quem emite uma mensagem e, que nessa, não haja esquivos linguísticos em relação ao objeto pesquisado (CAREGNATO \& MUTTI, 2006).

Destaca-se que a abordagem qualitativa com o uso da análise de conteúdo requer uma delimitação específica do objeto de estudo para evitar induções, a priori, dos significados utilizados nos respectivos artigos em análise. Portanto, a análise empreendida consistiu em identificar o conceito de ensino utilizado e a articulação desse conceito ao corpo do artigo, evitando assim outras interpretaçõessenão aquelasdecorrentes da linguagem empregadapelos autores em referência ao conceito de ensino.

\section{DAdos E Discussões}

Nas análises dos trabalhos que foram objeto deste estudo, procura-seimprimir, em parte ou em sua totalidade, os itens descritos nos procedimentos metodológicos que serviram de base para as inferências feitas em consonância com os objetivos propostos. Destaca-se que alguns 'entendimentos'empregados para sustentar as análises foram retirados dos próprios trabalhos.Tais afirmações são recorrentes nos artigos analisados e aqui selecionadas as que melhor expressam o conjunto discursivo.

É importante destacar que a área temática de Educação e Pesquisa em Contabilidade (EPC) congrega, em uma mesma seção, trabalhos que procuram discutir o "Ensino" e a "Pesquisa" dentro da área contábil. Este estudo, ao restringir sua amostra aos trabalhos cujo tema central é o ensino, evidencia que apenas uma minoria dos trabalhos dessa seção dedica-se a discutir assuntos relacionados ao processo ensino-aprendizagem em contabilidade, conforme apresenta a Tabela 2.

Tabela2. Quantidade de Artigos

\begin{tabular}{|l|l|l|l|l|l|l|l|l|l|l|l|l|l|l|}
\hline & $\mathbf{2 0 0 7}$ & $\mathbf{2 0 0 8}$ & $\mathbf{2 0 0 9}$ & $\mathbf{2 0 1 0}$ & $\mathbf{2 0 1 1}$ & $\mathbf{2 0 1 2}$ & $\mathbf{2 0 1 3}$ & $\mathbf{2 0 1 4}$ & $\mathbf{2 0 1 5}$ & $\mathbf{2 0 1 6}$ & $\mathbf{2 0 1 7}$ & $\mathbf{2 0 1 8}$ & $\mathbf{2 0 1 9}$ & Total \\
\hline $\begin{array}{l}\text { Artigos na } \\
\text { área } \\
\text { temática } \\
\text { EPC }\end{array}$ & 5 & 6 & 19 & 16 & 21 & 18 & 18 & 15 & 19 & 25 & 29 & 18 & 12 & $\mathbf{2 2 1}$ \\
\hline $\begin{array}{l}\text { Artigos } \\
\text { utilizam } \\
\text { termo } \\
\text { ensino }\end{array}$ & 2 & 3 & 6 & 5 & 6 & 7 & 5 & 8 & 14 & 11 & 16 & 11 & 7 & $\mathbf{1 0 1}$ \\
\hline $\begin{array}{l}\text { Artigos } \\
\text { que } \\
\text { aproximam } \\
\text { umconceito } \\
\text { de ensino }\end{array}$ & $\mathbf{2}$ & $\mathbf{3}$ & $\mathbf{4}$ & $\mathbf{2}$ & $\mathbf{2}$ & $\mathbf{5}$ & $\mathbf{3}$ & $\mathbf{5}$ & $\mathbf{7}$ & 5 & 7 & 2 & 2 & $\mathbf{4 9}$ \\
\hline
\end{tabular}

Fonte: Dados da Pesquisa 
Desses artigos, denota-se que existem trabalhos que, mesmo possuindo o "ensino em contabilidade" como tema proposto,não fazem referência, implícita ou explicita, quanto ao entendimento sobre o conceito de ensino adotado, tendo sido esses, excluídos da amostra.

Os assuntos que norteiam as discussões acerca do "ensino"no congresso ANPCONT durante o período em análise envolvem questõesa respeito da organização eda estrutura curricular, estilos de aprendizagem, métodos e práticas de ensino, saberes necessários à docência, adequação da proposta curricular às exigências do mercado, fatores que afetam o desempenho acadêmico, fatores psicológicos do processo de ensino, metodologias de ensino, avaliação do processo de ensino, qualificação docente, motivações de aprendizagem, bem como o desenvolvimento de competências e habilidades. Contudo, não se pretende com isso oferecer um delineamento do perfil da produção no referido congresso, mas indicar uma aproximação ao contexto no qual emergem as concepções de ensino dentro da área contábil no congresso em análise, visto que os assuntos que circundam as discussões sobre o ensino podem oferecer subsídiosao debate e ao entendimento das concepções adotadas.

As definições de ensino utilizadas pelos autores para sustentar as discussões nos trabalhos analisados seguem, em sua essência, basicamente três entendimentos distintos que se repetem ao longo dos estudos:

a) No primeiro deles, o ensino é visto como um processo capaz de criar e moldar competências voltadas a suprir as demandas do mercado de trabalho. Tal concepção é compartilhada por vinte e cinco(25) dos trabalhos.

b) No segundo, o ensino é entendido como um processo cumulativo na aquisição de conhecimento com a finalidade primordial de preparar os indivíduos para a atuação profissional. Dezesseis (16) trabalhos compartilham desse entendimento.

c) Por fim, oito (8) trabalhos abordam o ensino como processo abrangente e construtivo no desenvolvimento da capacidade crítica e criativa na formação de um sujeito inserido socialmente, capaz de analisar criticamente a realidade que o circunda.

A utilização do conceito de ensino, nessas classificações,como finalidade específica demonstra impressões iniciais do seu entendimento. Com base nas percepções evidenciadas em cada trabalho, foi possível identificar os subsídios nos quais os autores se pautam para definir uma concepção do processo ensino-aprendizagem, voltado a atingir tal fim. Tais informações possibilitaram que os trabalhos analisados fossem classificados de acordo com a abordagem de ensino predominante, sendoessesordenados em cinco abordagens: Tradicional, Comportamentalistas, Humanista, Cognitivista e Sociocultural, conforme exposto na Tabela 3.

Tabela3. Concepções Adotadas

\begin{tabular}{|l|l|l|l|l|l|l|l|l|l|l|l|l|l|l|}
\hline Concepções & $\mathbf{2 0 0 7}$ & $\mathbf{2 0 0 8}$ & $\mathbf{2 0 0 9}$ & $\mathbf{2 0 1 0}$ & $\mathbf{2 0 1 1}$ & $\mathbf{2 0 1 2}$ & $\mathbf{2 0 1 3}$ & $\mathbf{2 0 1 4}$ & $\mathbf{2 0 1 5}$ & $\mathbf{2 0 1 6}$ & $\mathbf{2 0 1 7}$ & $\mathbf{2 0 1 8}$ & $\mathbf{2 0 1 9}$ & Total \\
\hline Tradicional & & & & & & 2 & & & & & & & & 2 \\
\hline $\begin{array}{l}\text { Comporta } \\
\text { mentalista }\end{array}$ & 2 & 1 & 2 & & 1 & 1 & 2 & 2 & 6 & & 2 & & & 22 \\
\hline Humanista & & & & 1 & & & 1 & & 1 & & & & & 3 \\
\hline $\begin{array}{l}\text { Cognitivist } \\
\text { a }\end{array}$ & 2 & & 1 & 1 & 1 & & 3 & & 2 & 1 & 1 & 1 & 13 \\
\hline $\begin{array}{l}\text { Sociocultur } \\
\text { al }\end{array}$ & & 2 & & & 1 & & 1 & & & 1 & 2 & 1 & 9 \\
\hline Total & $\mathbf{2}$ & $\mathbf{3}$ & $\mathbf{4}$ & $\mathbf{2}$ & $\mathbf{2}$ & $\mathbf{5}$ & $\mathbf{3}$ & $\mathbf{6}$ & $\mathbf{7}$ & $\mathbf{4}$ & $\mathbf{4}$ & $\mathbf{4}$ & $\mathbf{3}$ & $\mathbf{4 9}$ \\
\hline
\end{tabular}

Fonte: Dados da Pesquisa

A primeira questão a ser ressaltada quanto àTabela 2 refere-se ao fato de que tal classificação expressa apenas a concepção predominante sobre o ensino, uma vez que o ideário pedagógico adotado pelos trabalhos não segue claramente uma única corrente, denotando certa confusão entre as abordagens, em quese identificam diversas tendências dentro de um mesmo referencial. Nesse sentido, entende-se que 
tal confusão conceitual implica um reducionismo ou mesmo na distorção do processo pedagógico a um fazer técnico. A compreensão dos componentes constitutivos do processo educacional é fundamental na formulação do projeto pedagógico e para sua implementação na formação profissional (LAFFIN, 2015, p.9).

Apesar de as abordagens se diferenciarem em sua concepção, a maioria dos trabalhos pormenoriza o ensino com a finalidade de desenvolver habilidades para atender as necessidades do mercado de trabalho. Mesmo aqueles que se revestemcom uma abordagem cognitivista ou humanista, encontram suporte em pressupostos voltados ao desenvolvimento de aptidões profissionais como sendo este o principal objetivo do ensino.

Ao identificar os teóricos utilizados para dar suporte aos conceitos de ensino empregados, constatouse que na maioria dos trabalhos os autores mencionadospara referenciar o ensino são da própria área contábil, sem fundamentos da epistemologia educacional, referindo-se ao ensino numa visão pragmática que encontra ressonância na racionalidade técnica.

\subsection{Tangenciando O Conceito De Ensino E Suas Abordagens}

Ao abordar o ensino de forma desprovida de bases teóricas críticas que sejam capazes de contextualizar as implicações das discussões no processo ensino-aprendizagem, os autores apoiam os argumentos principalmente em pressupostos da abordagem comportamentalista do ensino com o principal objetivo de moldar os indivíduos às demandas do mercado de trabalho. Nesse sentido, ratifica-se que

as maneiras de trabalhar no ensino superior de contabilidade, geralmente pautadas na racionalidade técnica, com ênfase demasiada no fazer, com pouca ou nenhuma relação com fundamentos teóricos, acabam por produzir ações desprovidas de consistência e de argumentos e, portanto, incapazes de legitimar a ciência contábil como indispensável na reorganização política e social (LAFFIN, 2010, p.16).

Convém ponderar que apredominância de um viés comportamentalista nos artigos analisados, compreendendo o ensino essencialmente como o desenvolvimento de competências profissionais, em que o processo ensino-aprendizagem assume o papel de transmitir determinados atributos básicos ao exercício da profissão, é sustentada por um discurso quase que único no entendimento de que a função do curso de Ciências Contábeis é"formar profissionais capacitados com habilidades e conhecimentos adequados para o exercício da profissão, pois o mercado de trabalho exige cada vez mais do profissional contábil", Artigo $n^{\circ} 29$ Anexo 1.

Tais posicionamentos reforçam o reducionismo do processo educativo em um elemento meramente curricular, demonstrado principalmente por trabalhos que se focam evidenciar as lacunas existentes entre as propostascurriculares frente às exigências do mercado de trabalho em uma perspectiva de que o currículo tenha como finalidade "aprimorar os conhecimentos do profissional contábil, focando o ensino nas necessidades do ambiente de negócios" Artigo $n^{\circ} 29$ Anexo 1.

Essa visão puramente mecanicista desconsidera o processo ensino-aprendizagem como um processo complexo, que extrapola a disposição curricular,ignoraque "o currículo não se constitui em um elemento neutro de transmissão desinteressada do conhecimento social. Antes, o currículo implica relações de saber, transmite visões sociais particulares e interessadas, produz identidades individuais e sociais particulares(SILVA e MOREIRA, 2008, p. 7) ". É preciso, incialmente, compreender que "não se pode exigir competência como coisa dada naturalmente, prevista e disponível num conjunto de disciplinas e conteúdos sem relação de interconexões com o contexto de atuação e de conhecimentos sistematizados (LAFFIN, 2015, p.17)".

A preocupação em expressar as demandas do mercado em uma proposta curricular encontra ressonância nas próprias diretrizes curriculares do curso de Ciências Contábeisque, buscando suprir as necessidades do mercado de trabalho, instituiu um processo de formação baseado em competências. "Essa tensão que se estabelece entre as competências exigidas na formação para responder ao mercado de trabalho destitui o entender da dimensão conceitual do conhecimento contábil em detrimento da racionalidade técnica que se resume a fazer" (LAFFIN, 2015, p. 21).

Os pressupostos comportamentalistas identificados nos artigos desta pesquisa, resultantes das exigências de um perfil profissional, assumem uma concepção de transmissão do conhecimento no 
sentido de desenvolver habilidades individuais, preocupando-se essencialmente na adaptação do indivíduo ao meio que o circunda, impondo assim, limites ao desenvolvimento da consciência crítica e da autonomia do indivíduo.

Ao definir o processo de ensino, baseando-se em uma prerrogativa caracterizada pela racionalidade técnica na busca pelo desenvolvimento de competências que certificam o contador ao exercício da profissão contábil, deixam de considerar a "dimensão substantiva do exercício profissional que deve estar aliado à dimensão da cidadania em função das relações que a atividade contábil mantém com os processos econômicos financeiros da gestão patrimonial e com consequências para a sociedade(LAFFIN, 2015, p.17)".

Deve-se considerar ainda que a qualificação do acadêmico de ciências contábeis, destacada pelos trabalhos em análise, estende-se como a capacidade de inserção no mercado de trabalho, sendo necessário contextualizar a configuração da profissão contábil atualmente para compreender as implicações educacionais frente às expectativas do mercado. "Ainda que a formação no ensino superior ultrapasse a visão tecnicista e da prática profissional, envolvendo a questão da cidadania, da responsabilidade social, do espaço reflexivo e de construção do conhecimento, estamos diante de um desafio no âmbito da interação entre a estrutura formativa e a possibilidade de atuação" Artigo $n^{\circ}$ 29 Anexo 1.

No Brasil, a migração de um modelo baseado em regras para um modelo baseado em princípios, a partir do processo de convergência aos padrões das normas internacionais,altera a prática contábil, passando de um processo essencialmente técnico a um contexto no qual o profissional contábildeverá possuira capacidade crítica na interpretação de normas e princípios contábeis, emitindo parecer técnico profissional, o que exigeuma sólida formação conceitual e cidadã.

O entendimento de uma nova conjuntura profissional encontra subsídios nas falas dos trabalhos utilizados, compartilhando o entendimento de que o cenário no qual a contabilidade atua "incorpora mudanças nas atitudes sociais, o progresso da tecnologia da informação e a utilização dos novos métodos, como os quantitativos e os das ciências sociais. Por isso, a contabilidade estaria migrando de sua base tradicional direcionada à escrituração, preparação de demonstrações e orçamentos, para um papel mais voltado ao gerenciamento, enfatizando sua importância social", Artigo $n^{\circ} 2$ Anexo 1 .

A compreensão de uma nova contextualização da profissão contábil, consequentemente acarreta a descrição de um novo perfil profissional com "capacidade cognitiva e com competências sociais de nível elevado, assim como flexibilidade, autonomia, polivalência e disposição para adequação a ocorrências novas" Artigo $n^{\circ} 4$ Anexo 1 "capaz de fazer julgamentos estratégicos no momento de apurar e apresentar os relatórios financeiros e gerenciais, guiados agora por princípios e não mais por regras preestabelecidas e inflexíveis, manuais prescritivos, como um processo mecânico, demasiadamente técnico" Artigo n 20 Anexo 1.

O conjunto discursivo, representativo dessas falas, demonstram a compreensão de um cenário não mais submetido à racionalidade técnica, no qual a contabilidade altera as práticas, buscando acompanhar as mudanças do ambiente econômico. Depreende-se quepara este cenário de mudanças, torna-se necessário aprofundar os aspectos da formação contábil, em uma perspectiva que supere a centralidade no fazer. Esse entendimento encontra subsídios nas afirmações de que "omodelo de educação, caracterizado como disciplinar e fragmentado, está esgotado e não consegue gerar

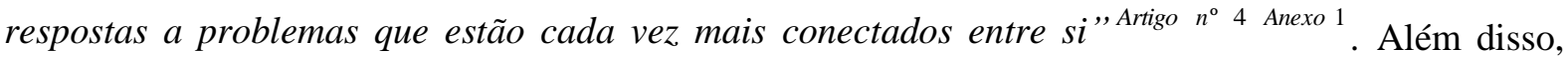
"profissionais com senso crítico e com conhecimento amplo capaz de opinar em diversas áreas de uma organização, fundamentam a importância de se examinar as estratégias e práticas de ensino utilizadas", Artigo $n^{\circ} 20$ Anexo 1

Também há os trabalhos que apresentamcríticas ao atual modelo no qual o ensino contábil se baseia, expressando pelo condicionamento do ensino contábil a lógica da racionalidade técnica em que "oensino da contabilidade se assemelha a uma espécie treinamento técnico em que o trabalho do professor é o de transmitir (expor e exemplificar) como se aplicam regras e operações aos fatos estruturados e idealizados da prática profissional. A orientação técnica, por sua vez, parte da consideração de que o professor é um sujeito técnico que deve dominar conhecimentos, atitudes e o saber-fazer úteis e necessários para ensinar", Artigo $n^{\circ} 33$ Anexo 1. 
Entretanto, apesar das críticas ao atual sistema, os trabalhos analisados neste estudo, ao tentar ressignificar o processo de ensino na busca de concepções abrangentes que sejam capazes de superar o modelo mecanicista e técnico da formação contábil, sustentam os argumentos em pressupostos comportamentalistas, compartilhando a visão do ensino como um treinamento mecânico que busca imprimir no processo as necessidades do capital.

Ressaltam-se que "novos paradigmas produtivos justificam a necessidade de um repensar constante nos conteúdos curriculares e nas práticas pedagógicas dos cursos" Artigo n 2 Anexo 1 "Por conseguinte, procura adaptar-se às reivindicações do mercado e busca proporcionar a qualificação dos alunos desse curso. $O$ desafio é ampliar o trabalho envolvendo os educadores, em um processo de integração das disciplinas do currículo entre si, com a realidade externa" Artigo $n^{\circ} 4$ Anexo 1 "metodologias de ensino devem acompanhar essa tendência e demanda do mercado" Artigo no 20 Anexo 1.

Encontra-se,nos trabalhos utilizados, demasiada preocupação em ajustar o processo de ensino às necessidades profissionais. Contudo, estão ausentes as discussões de como preparar um sujeito em condições de participar e acompanhar as mudanças do mundo social e profissional. Este posicionamento submetido à lógica do mercado acaba por introduzir um processo formativo voltado a uma perspectiva técnica em detrimento a uma formação técnico-científica, com a compreensão social da profissão, visto que a adoção de uma concepção voltada à lógica do mercado

esvazia o conteúdo teórico-metodológico das disciplinas e centra-se apenas no operacional técnico da profissão. É uma concepção restrita da formação em função de prover o estudante apenas na superfície do fazer, destituindo da formação o alcance das relações da ciência e da tecnologia com a sociedade. Essa formatação específica no plano da graduação imobiliza o estudante e o trabalhador frente às mudanças e convergências dos processos produtivos baseados em ciência e tecnologia [...] (LAFFIN, 2015, p.3)

Depreende-se, nesse sentido, que ao exigir a polivalência na formação do estudante em decorrência a reestruturação do modelo de produção, ou seja, na formação baseada no fazer evoltada ao desenvolvimento de competências, implica orompimento da possibilidade de que o estudante compreenda as condições do cenário profissional e social no qual está inserido (LAFFIN, 2015, p.20). Assim, os limites impostos por uma abordagem pedagógica com foco nas competências levam alguns dos trabalhos em análise a se contrapor a essaconcepção de ensino, demonstrando discordância com aideia da simples transferência do conhecimento em uma concepção educacional passiva, modelo predominante no cenário da educação contábil.

Tal oposição reflete a compreensão de que

"Ensinar quer dizer ajudar e apoiar os alunos a confrontar uma informação significativa e relevante no âmbito da relação que estabelecem com uma dada realidade, capacitando-o para reconstruir os significados atribuídos a essa realidade e a essa relação [...] práticas sociais em que professores trabalham em interação e relação com outros sujeitos (alunos, outros professores e outros profissionais das escolas), em ambientes especificos (escolas, universidades) e em função de um objetivo claro de mudança como resultado esperado: transformar os alunos, educando-os, tanto num sentido amplo quanto estrito [...]" Artigo $n^{\circ} 33$ Anexo 1

Tais referênciasdestacam o esgotamento dos modelos baseados na racionalidade técnica, apontando para o entendimento de que o ensino não deve simplesmente acompanhar as mudanças do mercado de forma desprovida de contextualização. Depreende-se que as alterações profissionais sugerem, não somente alterações curriculares no ensino, mas sim, um novo modo de pensar a educação, com a adoção de abordagensque envolvama participação ativa do aluno no processo de ensino em uma concepção pedagógica que ultrapasse a formação técnica e prepare o indivíduo para aapropriação dos conhecimentos técnicos e científicos da contabilidade, compreendendo as relações sociais no qual está inserido.

\subsection{O Conceito De Ensino Em Movimentos Hibridos}

Os artigos apresentados a partir do ano de 2016 na categoria Educação e Pesquisa em Contabilidade e que utilizam no título e no corpo do texto o termo 'ensino' não discutem o conceito de ensino. $\mathrm{O}$ termo é utilizado, mas seu conceito, definição ou característica do processo de ensino não são apresentados. A palavra ensino é utilizada para indicar a formação a partir dos 'níveis de ensino' para 
a 'atuação profissional', sem, contudo, dimensionar o ensino como ação intencional e, portanto, distante do seu caráter pedagógico.

A utilização do termo 'ensino' aparece nos diferentes artigos, seja para inferir sobre aspectos relacionados ao 'processo ensino-aprendizagem' ou 'as modalidades do ensino'. O termo "ensino" é utilizado para referenciar 'metodologia de ensino' sem, contudo, discutir o processo que o constitui. Nos casos em que o termo é utilizado pelo uso de 'metodologias ativas', não se discutem o "ensino", mas atribuem-se às metodologias uma certa responsabilidade pelo resultado do processo, antagonizando e externalizando a participação dos professores e estudantes. O termo 'ensino' apresentado nos trabalhos que se faz inferências, tangenciam uma fluência de conotações comportamentalista.

No ano de 2017 os trabalhos apresentados na linha Educação e Pesquisa em contabilidade ao referenciar o termo 'ensino' passam a assumir um discurso progressista e situando o ensino nas abordagens cognitivista e sociocultural. Esse transito entre as duas abordagens pode ter indícios na participação de titulações de diferentes áreas na produção dos trabalhos e decorrentes dessa integração uma percepção de que o ensino passa a incorporar uma categoria de trabalho que é o trabalho do professor.

No conjunto dos trabalhos que utilizam o termo 'ensino' existe ainda um deslocamento do ensino para as 'metodologias ativas' e suas possibilidades. O 'ensino' assume uma conotação de 'estratégias de ensino' pelas quais buscam uma articulação entre teoria e prática. Nesta acepção de ensino, configuram-se as demandas da atualidade da profissão as quais buscam uma articulação com o perfil do currículo vigente.

Ao compreender a 'pesquisa' como uma concepção de ensino e possibilidade de mudanças do trabalho do professor, e nisto uma 'reconstrução' da prática pedagógica, contudo denota-se nos dados da pesquisa ainda certa prevalência da abordagem tradicional à compreensão do ensino.

É perceptível um certo desconforto de alguns autores no cotejamento entre discursos teóricos delineados na perspectiva sociocultural com o resultado de suas pesquisas que remetem a práticas tradicionais. Parece haver uma tensão entre práticas que discutem o ensino como emancipatório, porém as estratégias que adotam na busca por novas formas de trabalho docente e na busca por atualizações pedagógicas sem, contudo, discutir o conteúdo do ensino.

Na discussão sobre 'metodologias de ensino' há referências da necessária integração da contabilidade com outras áreas do conhecimento mesmo que os resultados de suas pesquisas ainda não encontrem ressonância com as concepções de ensino delineadas.

Os trabalhos apresentados em 2018 na linha Educação e Pesquisa em Contabilidade que utilizam o termo 'ensino' nas proximidades do processo de ensino caracterizam a compreensão do termo como 'processo ensino-aprendizagem' como síntese de 'algo' coletivamente apreendido. A partir dessa percepção utilizam essa 'compreensão abstrata' para inferir sobre 'novas formas de avaliação do processo de ensino', 'identificar características geracionais' e 'demográficas' intervenientes no ensino.

A utilização do termo 'ensino' é preponderante como tradução de 'estratégias de ensino'sobretudo na discussão sobre as'metodologias ativas', buscando contrapor práticas 'inovadoras' com abordagens tradicionais. Contudo, ao apresentarem exemplos diferenciados de abordagem de conteúdos das disciplinas de contabilidade, a análise dos dados dessas pesquisas se configuram um resultado mecânico com ênfase de avaliação das metodologias e não de abordagens sobre o 'ensino'.

Em 2019 o termo 'ensino' na linha Educação e Pesquisa em Contabilidade não teve expressão quantitativa e também não difere de abordagens em anos anteriores. Sua utilização está na percepção de que as 'exigências do mercado de trabalho' estão mais próximas de alguns 'conteúdos e disciplinas' de que na formação integral. Dessa interpretação, as 'estratégias de ensino' são mobilizadoras de motivação para a aprendizagem.

Outros usos do termo 'ensino' buscam no 'processo de ensino' convergências para formação de profissional para atuação em nível mundial visando atender as demandas de organismos internacionais e com isto pressionar uma certa configuração de currículo. 
Ainda o 'processo ensino-aprendizagem' pautado pela compreensão de 'competências', assume um lugar de análise de perfis de professores e de suas experiências com a docência dando a compreender que a 'aprendizagem dos estudantes' deva ser similar às competências de formação previstas nas diretrizes curriculares para a formação do contador.

Ainda nestas abordagens são delineadas para as 'metodologias ativas' certas atribuições que deslocam o estudante de sua mobilização para a aprendizagem e um certo esvaziamento das atividades do professor no trabalho com o ensino.

Apesar de as abordagens alternativas terem sido apontadas nos trabalhos analisados, o inventário do conceito de ensino averiguado por este estudo indica que a maioria deles que serviram como objeto do estudo adota uma concepção de ensino voltada a produção de habilidades profissionais com um viés mecanicista do processo, característico do curso de ciências contábeis.

Ainda que alguns dos trabalhos que se revelem contrários a tal entendimento acerca do ensino, baseiam os argumentos em concepções que procuram ajustar o sujeito ao ambiente com o único propósito de atender as necessidades do mercado de trabalho, sem se preocupar com o desenvolvimento da compreensão da realidade que o circunda para a participação efetiva do aluno como um sujeito socialmente inserido.

Essa constatação sugere uma limitação quanto às concepções pedagógicas do ensino adotada nos trabalhos com a implicação de que novas alternativas para o entendimento do processo ensinoaprendizagem em contabilidade sejam inibidas.

Nesse sentido, adota-se o entendimento de que

épreciso, portanto, promover ações no ensino da contabilidade que busquem superar a dicotomia entre teoria e prática e que configurem a graduação como o lugar de referência da produção e da pesquisa. Tal posicionamento implica em redimensionar a prática docente que ainda hoje se fundamenta em transmissão/recepção, já que uma educação de qualidade pressupõe ser construtiva e participativa, deixando o aluno de ser um objeto da manifestação da aprendizagem para ser participante do processo construtivo do conhecimento, tanto quanto o professor. (LAFFIN, 2005, p.171)

As novas configurações sociais da profissão indicam a necessidade de uma proposta atual para a educação em contabilidadecapaz de inserir o sujeitoà participação social apropriando-o do conhecimento contábil e para além do exercício da profissão contribuir com o desenvolvimento da ciência contábil (LAFFIN, 2015).

\section{CONCLUSÃo}

Este estudo objetivou identificar qual é a concepção de ensino que fundamenta os trabalhos apresentados nas edições do ANPCONT no período de 2007 a 2019 na área temática de "Educação e Pesquisa em Contabilidade". Para tanto, analisaram-se40 artigos que se propuseram abordar questões relativas ao processo ensino-aprendizagem em contabilidade e fizeram referência, de forma implícita ou explicita, acerca do conceito de ensino.

A análise discursiva empregada demonstrou que dos trabalhos analisados, vinte e cincocompreendem o ensino como um processo capaz de criar e moldar competências voltadas a suprir as demandas do mercado de trabalho; dezesseisadotam o entendimento de que o ensino é um processo cumulativo na aquisição de conhecimento com a finalidade primordial de preparar os indivíduos para a atuação profissional e oitoabordam o ensino como processo abrangente e construtivo no desenvolvimento da capacidade crítica e criativa na formação de um sujeito inserido socialmente, capaz de analisar criticamente a realidade que o circunda.

Embora concepções de ensino distintas terem sido identificadas, a maioria dos trabalhos pormenoriza o ensino com a finalidade de desenvolver habilidades e competências para atender as necessidades do mercado de trabalho, ancorando-se em pressupostos comportamentalistas que buscam expressar no processo ensino-aprendizagem as necessidades do capital.

Em vista disso, constatou-se que os trabalhos analisados, em sua maioria, não seguem um ideário pedagógico com concepções definidas. Por outro lado, identificaram-se diversas tendências dentro de um mesmo referencial, as quais geralmente se baseiam em autores da própria área contábil, sem 
fundamentos da epistemologia educacional. Como consequência, os trabalhos referem-se ao ensino de forma desprovida de bases teóricas críticas, ancorando-se em basesprovenientes da vivência ou da própria prática contábil, definindo o ensino numa visão pragmática que encontra ressonância na racionalidade técnica.

A partir do ano de 2016 observa-se um discurso sobre 'ensino' que passa a ser subentendido pelos termos 'processo ensino-aprendizagem', 'estratégias de ensino' e 'metodologias de ensino' com prevalência para a utilização do termo 'metodologias ativas'. Esse deslocamento do termo 'ensino' impõe um deslocamento de compreensão do 'processo ensino-aprendizagem' produz um distanciamento na articulação de concepções teórico-práticas dos componentes constitutivos da organização pedagógica do ensino e convergem, para além das iniciativas, um retorno as práticas tradicionais.

Por outro viés, ainda que de modo muito restrito e incipiente encontram-se manifestações a partir de escolhas de bases referenciais críticas bem como em descrição de dados qualitativos de pesquisas que indicam uma efetiva necessidade de melhor compreender os componentes do processo pedagógico que envolve estudantes e professores em Ciências Contábeis.

Ainda, como conclusão defende-se a compreensão de ensino como um processo histórico que tem se desenvolvido ao longo dos processos educativos. Desse modo seu movimento resguarda as concepções e valores de cada tempo, bem como responde a dimensão de cultura e contexto no qual se manifesta como ato educativo. Enfatiza-se que o ensino ao corresponder aos objetivos educacionais é componente da prática pedagógica e que esta ao ser uma prática social enseja estar comprometida com as necessidades concretas de todos os sujeitos nela implicados. Dessa forma, acredita-se que o ensino na perspectiva crítica que enfatiza os aspectos políticos, sociais, econômicos e culturais dos objetivos educacionais e da prática pedagógica, promove as condições da formação técnicoprofissional e cidadã num percurso de emancipação dos sujeitos pelo qual na dialética é sempre inconclusa.

\section{REFERÊNCIAS}

[1] Bardin, L. (1979). Análise de conteúdo. (70. ed.) Lisboa.

[2] Caregnato, R. C. A., \& Mutti, R. (2006). Pesquisa qualitativa: análise de discurso versus análise de conteúdo. Texto Contexto Enferm, 15(4), 679-84.

[3] Fonseca, J. J. S. D. (2002). Metodologia da pesquisa científica. Fortaleza: UEC.

[4] Freire, P. (1997). Pedagogia da autonomia-Ed. Paz e Terra-São Paulo.

[5] Gerhardt, T. E., \& Silveira, D. T. (2009). Métodos de pesquisa. Porto Alegre: Editora da UFRGS.

[6] Laffin, M. (2005). De contador a professor: a trajetória da docência no ensino superior de contabilidade. Florianópolis: Imprensa Universitária.

[7] Laffin, M. (2010). Leitura: processo metodológico no ensino superior de contabilidade. Revista Brasileira de Contabilidade. $N^{\circ} 185$ set/out/2010. Brasília. p.41-54

[8] Laffin, M. (2015). Graduação em Ciências Contábeis-A Ênfase nas Competências: Contribuições ao Debate. Education Policy Analysis Archives,23(78), 1-30.

[9] Libâneo, J. C. (2004). Didática.São Paulo: Cortez.

[10] Minayo, M. C. D. S. (2007). O desafio do conhecimento (10.ed.) São Paulo: Hucitec.

[11] Mizukami, M. D. G. N. (1986). Ensino: as abordagens do processo. São Paulo: Editora Pedagógica e Universitária.

[12] Moraes, M. C. (2004). Pensamento eco-sistêmico: educação, aprendizagem e cidadania no século XXI. Petrópolis: Vozes.

[13] Nérici, I. G. (1985). Educação e ensino (Vol. 36). Ibrasa.

[14] Pérez Gómez, A.I. (1998). Ensino para a Compreensão. In Compreender e Transformar o ensino. Sacristán e Gómez. Porto Alegre, Ed. ArtMed.

[15] Saviani, D. (1997). Pedagogia histórico-crítica primeiras aproximações.Campinas: Autores Associados.

[16] Silva, T. T. Moreira, A. F. B. (2008). Currículo, cultura e sociedade (10. ed.) São Paulo: Cortez.

[17] Thiollent, M. (1988). Metodologia da pesquisa-ação. São Paulo: Cortez \& Autores Associados.

[18] Triviños, A. N. S. (1987). Introdução à pesquisa em ciências sociais: a pesquisa qualitativa em educação. São Paulo: Atlas. 


\section{Anexo 1-Trabalhos Selecionados}

\begin{tabular}{|c|c|c|c|}
\hline $\mathbf{N}^{\mathbf{0}}$ & Autores & Título & Ano \\
\hline 1 & Miranda et al. & $\begin{array}{l}\text { Estilos de Aprendizagem e sua Inter-relação com as Técnicas de Ensino: } \\
\text { uma Avaliação com o Modelo Vark no Curso de Ciências Contábeis de } \\
\text { uma IES no Interior Paulista }\end{array}$ & 2007 \\
\hline 2 & Capacchi et. al. & $\begin{array}{l}\text { A Prática do Ensino Contábil no Estado do Rio Grande do Sul: Uma } \\
\text { Análise da Grade Curricular Frente às Exigências Legais e Necessidades } \\
\text { Acadêmicas }\end{array}$ & 2007 \\
\hline 3 & Soares \& Araújo & $\begin{array}{l}\text { Aplicação do método de ensino Problem Based Learning (PBL) no curso } \\
\text { de Ciências Contábeis: um estudo empírico }\end{array}$ & 2008 \\
\hline 4 & $\begin{array}{l}\text { Althoff } \& \\
\text { Domingues }\end{array}$ & $\begin{array}{l}\text { Práticas interdisciplinares nos cursos de graduação em Ciências Contábeis: } \\
\text { mito ou realidade }\end{array}$ & 2008 \\
\hline 5 & $\begin{array}{l}\text { Oliveira Neto et. } \\
\text { al. }\end{array}$ & $\begin{array}{l}\text { Os estilos cognitivos na formação de estudantes em duas áreas de formação } \\
\text { acadêmica: Ciências Contábeis e Engenharia da Produção }\end{array}$ & 2008 \\
\hline 6 & Araújo et al. & $\begin{array}{l}\text { Saberes Necessários à Prática da Educação Problematizadora: A Pedagogia } \\
\text { da Autonomia de Paulo Freire no Curso De Ciências Contábeis }\end{array}$ & 2009 \\
\hline 7 & $\begin{array}{l}\text { Abhayawansa \& } \\
\text { Fonseca }\end{array}$ & $\begin{array}{l}\text { Conceptions of Learning and Approaches to Learning: An Exploratory } \\
\text { Study of a Culturally Distinct Group of Overseas Accounting Students }\end{array}$ & 2009 \\
\hline 8 & Pires et al. & $\begin{array}{l}\text { A Formação e a Demanda do Mercado de Trabalho do Contador na Região } \\
\text { Metropolitana de Porto Alegre/RS }\end{array}$ & 2009 \\
\hline 9 & Araújo et al. & $\begin{array}{l}\text { Fatores que Afetam o Processo de Ensino no Curso de Ciências Contábeis: } \\
\text { Um Estudo Baseado na Percepção dos Professores }\end{array}$ & 2009 \\
\hline 10 & $\begin{array}{l}\text { Nogueira } \\
\text { Espejo }\end{array}$ & $\begin{array}{l}\text { O impacto do estilo de aprendizagem no desempenho acadêmico: um } \\
\text { estudo empírico com alunos das disciplinas de contabilidade geral e } \\
\text { gerencial na educação a distância }\end{array}$ & 2010 \\
\hline 11 & Leal et al. & $\begin{array}{l}\text { Interdisciplinaridade no curso de ciências contábeis: os desafios e as } \\
\text { possibilidades de aprender e ensinar a partir de uma experiência }\end{array}$ & 2010 \\
\hline 12 & Catapan et al. & $\begin{array}{l}\text { Análise da percepção dos discentes sobre os docentes exemplares de } \\
\text { contabilidade em IES públicas e privadas }\end{array}$ & 2011 \\
\hline 13 & \begin{tabular}{|l|}
$\begin{array}{l}\text { Nascimento } \\
\text { Junqueira }\end{array}$ \\
\end{tabular} & $\begin{array}{l}\text { Análise do perfil do aluno de ciências contábeis na modalidade a distância } \\
\text { e do seu desempenho na disciplina contabilidade introdutória }\end{array}$ & 2011 \\
\hline 14 & Avelino et al. & $\begin{array}{l}\text { Desenvolvimento profissional de estudantes de ciências contábeis: análise } \\
\text { empírica sobre as intenções após a graduação }\end{array}$ & 2012 \\
\hline 15 & Cueva et. al & Representações de amor e ódio aos docentes brasileiros e paraguaios & 2012 \\
\hline 16 & \begin{tabular}{ll|} 
Souza $\quad \&$ \\
Vergilho
\end{tabular} & $\begin{array}{l}\text { Um perfil do profissional contábil na atualidade: estudo comparativo entre } \\
\text { conteúdo de ensino e exigências de mercado }\end{array}$ & 2012 \\
\hline 17 & Miranda et al. & $\begin{array}{l}\text { Ao mestre com carinho: relações entre as qualificações docentes e o } \\
\text { desempenho discente em contabilidade }\end{array}$ & 2012 \\
\hline 18 & \begin{tabular}{ll|} 
Nascimento \& \\
Cunha
\end{tabular} & $\begin{array}{l}\text { Flexibilidade nos estudos: a busca pela educação em cursos de formação } \\
\text { executiva na modalidade a distância }\end{array}$ & 2012 \\
\hline 19 & Lopes et al. & $\begin{array}{l}\text { Aspectos da motivação intrínseca e extrínseca: uma análise com discentes } \\
\text { de ciências contábeis da Bahia na perspectiva da teoria da } \\
\text { autodeterminação }\end{array}$ & 2013 \\
\hline 20 & Silva et. al. & $\begin{array}{l}\text { Concepções pedagógicas e mudanças nas práticas contábeis: um estudo } \\
\text { sobre o modelo educacional adotado em uma universidade pública e a } \\
\text { formação critico-reflexiva do contador }\end{array}$ & 2013 \\
\hline 21 & Vicente et al. & $\begin{array}{l}\text { Desempenho acadêmico inferior dos alunos do "fundão": mito ou } \\
\text { realidade? }\end{array}$ & 2013 \\
\hline 22 & Leal e Borges & $\begin{array}{l}\text { Estratégias e métodos aplicados no ensino da contabilidade: uma análise } \\
\text { dos planos de ensino do curso de ciências contábeis de uma instituição } \\
\text { pública brasileira }\end{array}$ & 2014 \\
\hline 23 & Martins et al. & $\begin{array}{l}\text { Avaliação de habilidades e de atitudes em abordagem de problem based } \\
\text { learning no ensino de controle gerencial }\end{array}$ & 2014 \\
\hline 24 & Nganga et. al. & $\begin{array}{l}\text { Mestres e doutores em salas de aula: eles estão sendo formados para } \\
\text { ensinar? }\end{array}$ & 2014 \\
\hline 25 & Silveira et. al. & $\begin{array}{l}\text { Fatores que afetam o desempenho no Enade em IES da cidade de } \\
\text { Uberlândia - MG: um estudo multicasos }\end{array}$ & 2014 \\
\hline 26 & Laffin, $\mathrm{M}$. & Ensinar conceitos em ciências contábeis & 2014 \\
\hline
\end{tabular}




\begin{tabular}{|c|c|c|c|}
\hline 27 & $\begin{array}{l}\text { Volpato } \\
\text { Guimarães }\end{array}$ & $\begin{array}{l}\text { A interdisciplinaridade como possibilidade no desenvolvimento de } \\
\text { competências na formação do contador }\end{array}$ & 2015 \\
\hline 28 & Oliveira et al. & $\begin{array}{l}\text { Análise comparativa entre os currículos das IFES brasileiras e a proposta } \\
\text { curricular do conselho federal de contabilidade }\end{array}$ & 2015 \\
\hline 29 & Silva et al. & Saberes docentes na visão de egressos do curso de ciências contábeis & 2015 \\
\hline 30 & Silva et al. & Comportamento e desempenho acadêmico no curso de ciências contábeis & 2015 \\
\hline 31 & Guelfi et al. & $\begin{array}{l}\text { Características do bom professor sob a ótica dos discentes de ciências } \\
\text { contábeis da geração y }\end{array}$ & 2015 \\
\hline 32 & $\begin{array}{l}\text { Frezzatti } \quad \& \\
\text { Martins }\end{array}$ & Pbl ou pbl's: a customização do mecanismo na educação contábil & 2015 \\
\hline 33 & Ferreira e Hillen & Aprendizagem docente de professores de contabilidade no ensino superior & 2015 \\
\hline 34 & Sousa et al & $\begin{array}{l}\text { Avaliação do ensino superior em ciências contábeis: validação do course } \\
\text { experience questionnaire(ceq) no contexto brasileiro }\end{array}$ & 2016 \\
\hline 35 & Silva et al & $\begin{array}{l}\text { Estratégias de aprendizagem autorregulada (srl) no ensino ead de } \\
\text { contabilidade }\end{array}$ & 2016 \\
\hline 36 & Campos et al & $\begin{array}{l}\text { Atuação dos doutores em contabilidade nos eixos ensino, pesquisa, } \\
\text { extensão, produção técnica e gestão à luz da teoria do capital humano }\end{array}$ & 2016 \\
\hline 37 & Santos et al & $\begin{array}{l}\text { Design thinkingcomo metodologia de ensino para a contabilidade } \\
\text { gerencial sob a abordagem construtivista: uma articulação teórica }\end{array}$ & 2016 \\
\hline 38 & Celestino et al & $\begin{array}{l}\text { Problem-based-learning (pbl) nos cursos de ciências contábeis das } \\
\text { instituições de ensino superior (ies) de natal/rn. }\end{array}$ & 2016 \\
\hline 39 & Souza et al & $\begin{array}{l}\text { O Ensino Da Contabilidade Geral No Brasil: Um Comparativo Entre } \\
\text { Regiões }\end{array}$ & 2017 \\
\hline 40 & Oliveira et al & $\begin{array}{l}\text { Análise Da Temática Contabilidade Tributária E/Ou Suas Assemelhadas } \\
\text { Na Formação Em Ciências Contábeis De Instituições De Ensino Superior } \\
\text { Localizadas No Estado De Minas Gerais }\end{array}$ & 2017 \\
\hline 41 & Bastos \& Peleias & $\begin{array}{l}\text { Interdisciplinaridade No Ensino De Perícia Contábil: Percepção Dos } \\
\text { Professores Em Cursos De Ciências Contábeis Na Cidade De São Paulo. }\end{array}$ & 2017 \\
\hline 42 & Santos et al & $\begin{array}{l}\text { Laboratório Contábil: O Uso Dessa Estratégia De Ensino Contribuiu } \\
\text { Para Minha Aprendizagem Prática? }\end{array}$ & 2017 \\
\hline 43 & Brandt et al & $\begin{array}{l}\text { Percepção Dos Docentes De Ciências Contábeis Em Relação Às } \\
\text { Metodologias Ativas No Ensino Superior. }\end{array}$ & 2017 \\
\hline 44 & Medeiros et al & $\begin{array}{l}\text { Metodologias Ativas De Ensino-Aprendizagem: A Experiência Da } \\
\text { Aplicação Dos Jogos De Empresas Em Uma Turma De Mestrado Em } \\
\text { Contabilidade. }\end{array}$ & 2017 \\
\hline 45 & Ferreira et al & $\begin{array}{l}\text { Pesquisa Enquanto Estratégia De Ensino Na Graduação Em Ciências } \\
\text { Contábeis }\end{array}$ & 2017 \\
\hline 46 & Luz et al. & $\begin{array}{l}\text { Avaliação do processo de ensino-aprendizagem emdisciplinas de } \\
\text { contabilidade: uma proposta construtivistacom base na percepção dos } \\
\text { discentes quanto à aprendizagem }\end{array}$ & 2018 \\
\hline 47 & Silva et al & $\begin{array}{l}\text { Estudo da utilização de estratégias de ensino ativas junto a alunos do } \\
\text { curso de ciências contábeis }\end{array}$ & 2018 \\
\hline 48 & Canton et al & 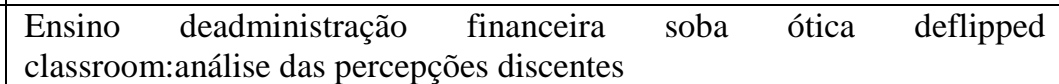 & 2019 \\
\hline 49 & Silva et al & $\begin{array}{l}\text { Aprendizagem colaborativa no ensino superior: umestudo com grupos } \\
\text { focais e mapa cognitivo sobre odesenvolvimento de habilidades por meio } \\
\text { da metodologiaativa team-based learning (tbl) }\end{array}$ & 2019 \\
\hline
\end{tabular}




\section{AUTHORS' BIOGRAPHY}

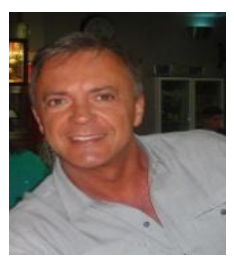

Marcos Laffin, Bacharel em Ciências Contábeis UNIVILLE, Licenciatura pela UDESC; Mestre pela UNICAMP; Doutor pela UFSC; Pós-doutorado em Contabilidade pela UFBA. Professor aposentado pelo Departamento de Ciências Contábeis da UFSC; atuou na Graduação e na Pós-graduação em Contabilidade. Coordenou o NETEC - Núcleo de Estudos Sobre Trabalho e Ensino em Contabilidade. Exerceu o cargo de Pró-reitor de Ensino de Graduação da UFSC 2004-2008 e foi Presidente do ForGrad - Fórum Nacional de Pró-reitores de Graduação das Universidades Brasileiras 2007-2008. É Pesquisador em Diretório de Pesquisas - Ensino de Contabilidade. Criou e desenvolveu a Revista Contemporânea de Contabilidade. ISSN 1808-1821 e ISSN e 2175-8069x. Categorias de interesse: Educação e Trabalho em Ciências Contábeis; Epistemologia Contábil; Ensino e Pesquisa em Ciências Contábeis.

http://lattes.cnpq.br/3230734469709272; https://orcid.org/0000-0003-3204-3817

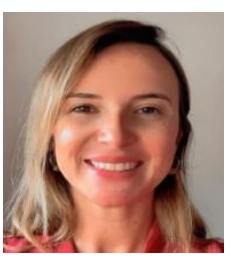

Nathália Helena Fernandes Laffin, Graduada em Ciências Contábeis pela Universidade Federal de Santa Catarina. Mestre em Administração pela Universidade do Estado de Santa Catarina. Doutora em Controladoria e Contabilidade pela Universidade de São Paulo.Professora do Curso de Ciências Contábeis da Faculdade Borges de Mendonça. Professora em Programas de Especialização Latu Sensu. Sócia da Make Time - Assistente Virtual. Diretora da área de BPO Financeiro.

http://lattes.cnpq.br/7847677877987516; https://orcid.org/0000-0003-1658-092X

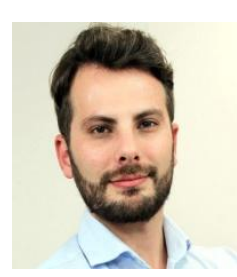

Jhonatan Hoff, Mestre em Contabilidade pela Universidade Federal de Santa Catarina (UFSC). É Professor Universitário e atualmente é Coordenador de cursos de Graduação na Faculdade FIPECAFI. Também atua como Consultor Empresarial e como docente em cursos de capacitação empresarial, empreendedorismo e gestão de negócios. Participou como mentor do Concurso Estadual de Ideias Inovadoras do SEBRAE/SC na estruturação e análise de ideias de negócio. Possui experiência com pesquisa científica e já atuou na área gerencial, financeira e fiscal.

http://lattes.cnpq.br/4237721091263401

Citation: Marcos Laffin, et.al. "Estado Do Conhecimento Sobre Ensino Na Contabilidade No Congresso Anpcont 2007-2019” International Journal of Humanities Social Sciences and Education (IJHSSE), vol 8, no. 7, 2021, pp. 154-169. doi: https://doi.org/10.20431/2349-0381.0807019.

Copyright: () 2021 Authors. This is an open-access article distributed under the terms of the Creative Commons Attribution License, which permits unrestricted use, distribution, and reproduction in any medium, provided the original author and source are credited. 